To the Editors:

\title{
Lack of granuloma formation in tuberculous lymphadenitis - clue to the diagnosis of human immunodeficiency virus infection
}

Since the emergence of acquired immune deficiency syndrome (AIDS), tuberculosis and human immune deficiency virus (HIV) infection have been intimately linked. Several studies have clearly shown that the incidence of active tuberculosis is increased in HIV infected patients (1). AIDS patients with tuberculosis have a higher incidence of extra-pulmonary and pleural disease. The most common sites of extra-pulmonary involvement are blood and extra-thoracic lymph nodes, followed by bone marrow, genitourinary tract and the central nervous system (2).

- A 53-year old man was seen with fever, loss of weight and loss of appetite of 2 months' duration. A left-sided supraclavicular lymph node measuring $1.0 \times 1.5 \mathrm{~cm}$ was found. No other lymph node groups were palpable. His haemoglobin was $10.2 \mathrm{~g} / \mathrm{dl}$. Except for an erythrocyte sedimentation rate of $106 \mathrm{~mm} /$ hour, all other investigations were normal. The purified protein derivative (PPD) test was nonreactive. The chest radiograph did not show any evidence of past or current pulmonary tuberculosis.

Histological examination of the lymph node removed at surgery showed extensive infiltration with histiocytoid cells. Large areas of caseous necrosis were also seen. The specimen was filled with numerous acid-fast bacilli. The Striking feature was the absence of granuloma formation. Subsequent investigations confirmed the diagnosis of HIV infection but his CD4 cell count was not done.

Since the manifestations of tuberculosis are frequently atypical in HIV infected patients early diagnosis may be difficult. Clinical and radiological findings of tuberculosis between HIV positive and HIV negative patients show a significant difference. However, these differences depend on the degree of immunodepression (1). HIV infected patients with a CD4 count of more than 200 may have typical clinical and radiological data and the PPD test is usually positive. Acid fast smears in sputum and typical granuloma in lymph nodes are found as frequently as in non-immunocompromised patients (3). This well-formed granuloma is composed of epitheloid cells, Langerhans giant cells and lymphocytes. In these lesions acid-fast mycobacteria are few and difficult to find (4), whereas in patients with lower CD4 counts clinical and radiological data are atypical. These include non-apical distribution of infiltrates, infrequent cavitation and increased frequency of hilar and mediastinal adenopathy (3).

When HIV infected patients are moderately immunosuppressed (CD 4 cell count less than 200) HIV infects both $\mathrm{T}$ cells and macrophages and thus impairs the host immune response by failing to secrete lymphokines that activate macrophages. Mycobacteria infected macrophages respond less well to the lymphokines. On histological examination of lymph nodes of these patients, granulomas are less well formed and contain more abundant acidfast bacilli (4).

Histologically the lack of classical granuloma formation and the negative PPD test indicate lack of immune reactivity and differential diagnosis should include HIV as well as neoplastic diseases such as lymphomas or metastatic carcinomas (2).

\section{References}

1. Havlir DY, Barnes PF. Tuberculosis in patients with human immunodeficiency virus infection. New England Journal of Medicine 1999; 340: 346-72.

2. Raviglione MC, O'brien RJ. Tuberculosis.In: Fauci AS, Braunwald $\mathrm{E}$, Isselbacher $\mathrm{KJ}$, et al. Eds. Harrison's principles of intemal medicine. $14^{\text {th }}$ ed. Vol. 1. New York: McGraw-Hill, 1998; 1005.

3. Markowitz N, Hanisen NI, Hopewell PC, et al. Incidence of tuberculosis in the United States among HIV-infected persons. Annals of Intemal Medicine 1997; 126: 123-32.

4. Samuelson J. Infectious diseases. In:Cotran RS, Kumar V, Collins T, Eds. Robbins pathological basis of diseases $6^{\mathrm{th}}$ ed. London: WB Saunders, 2000; 350-352.

H Karunatilake', N Thamilvannan', and H Wimalaratna ${ }^{3}$. 'Senior Registrar, ${ }^{2}$ Registrar and ${ }^{3}$ Physician, Teaching Hospital, Kandy. 